Supplement of Atmos. Chem. Phys., 18, 17475-17488, 2018

https://doi.org/10.5194/acp-18-17475-2018-supplement

(c) Author(s) 2018. This work is distributed under

the Creative Commons Attribution 4.0 License.

(c) (i)

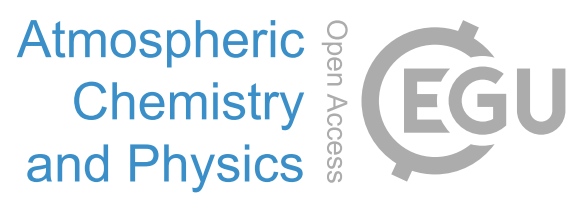

Supplement of

\title{
The efficacy of aerosol-cloud radiative perturbations from near-surface emissions in deep open-cell stratocumuli
}

Anna Possner et al.

Correspondence to: Anna Possner (apossner@ carnegiescience.edu)

The copyright of individual parts of the supplement might differ from the CC BY 4.0 License. 


\section{Figures}

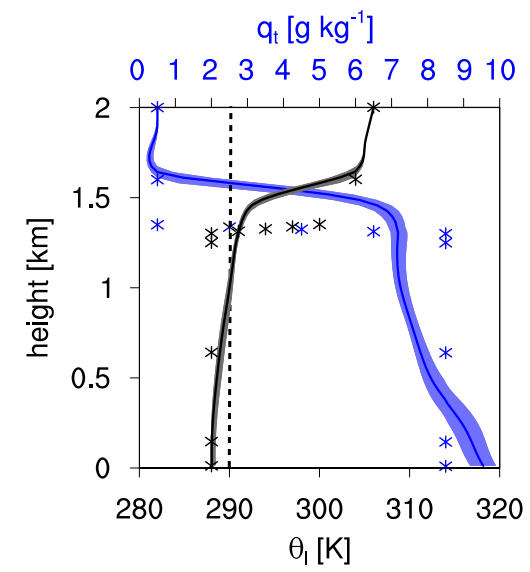

Figure S1. Simulated profiles of liquid potential temperature $\left(\theta_{l}\right.$, black) and total moisture content $\left(q_{t}\right.$, blue) for the $c t r l$ simulation. Median and interquartile range of profiles are shown for the entire simulated period $(45 \mathrm{~h})$. Hence, the spread captures the entire spatio-temporal variability of both entities throughout the simulation. Dashed line indicates $290 \mathrm{~K}$ isoline. Markers denote prescribed sounding at initialisation for $\theta_{l}$ (blue) and $q_{t}$ (black).
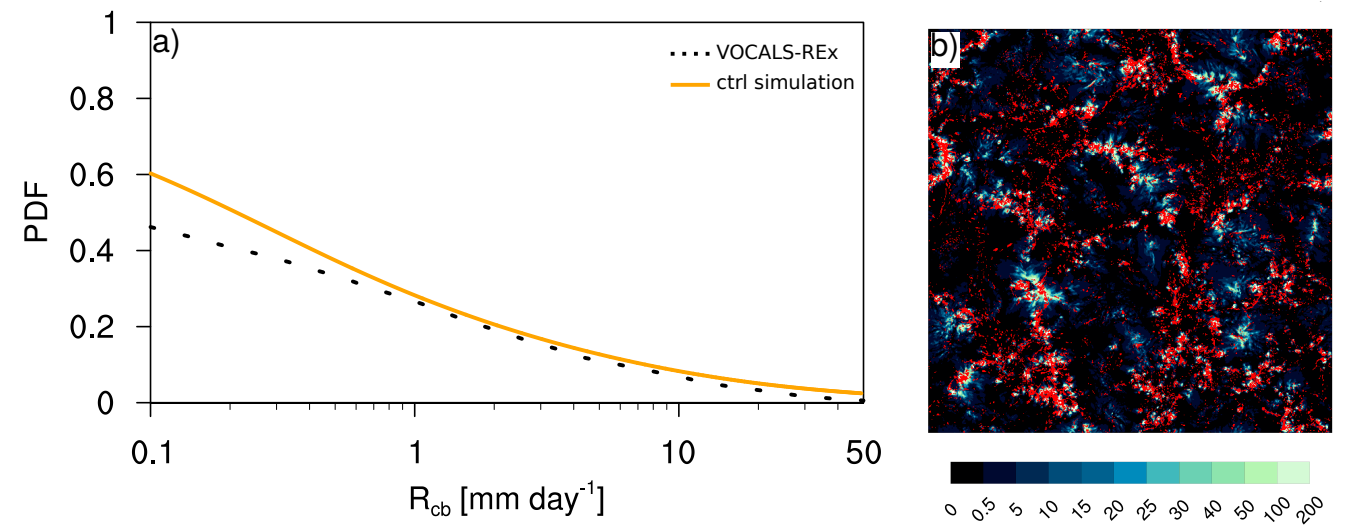

Figure S2. a) Probability distribution function (PDF) of cloud-base precipitation rate $\left(R_{c b}\right)$ obtained during campaign (Wood et al. (2011) denoted in black) and for VOCALS-REx simulations $c t r l$ simulation (yellow). b) Cloud-base precipitation field $\left(R_{c b}\right)$ in contours with updraft regions (vertical velocity $>0.5 \mathrm{~m} \mathrm{~s}^{-1}$ ) overlaid in red. 

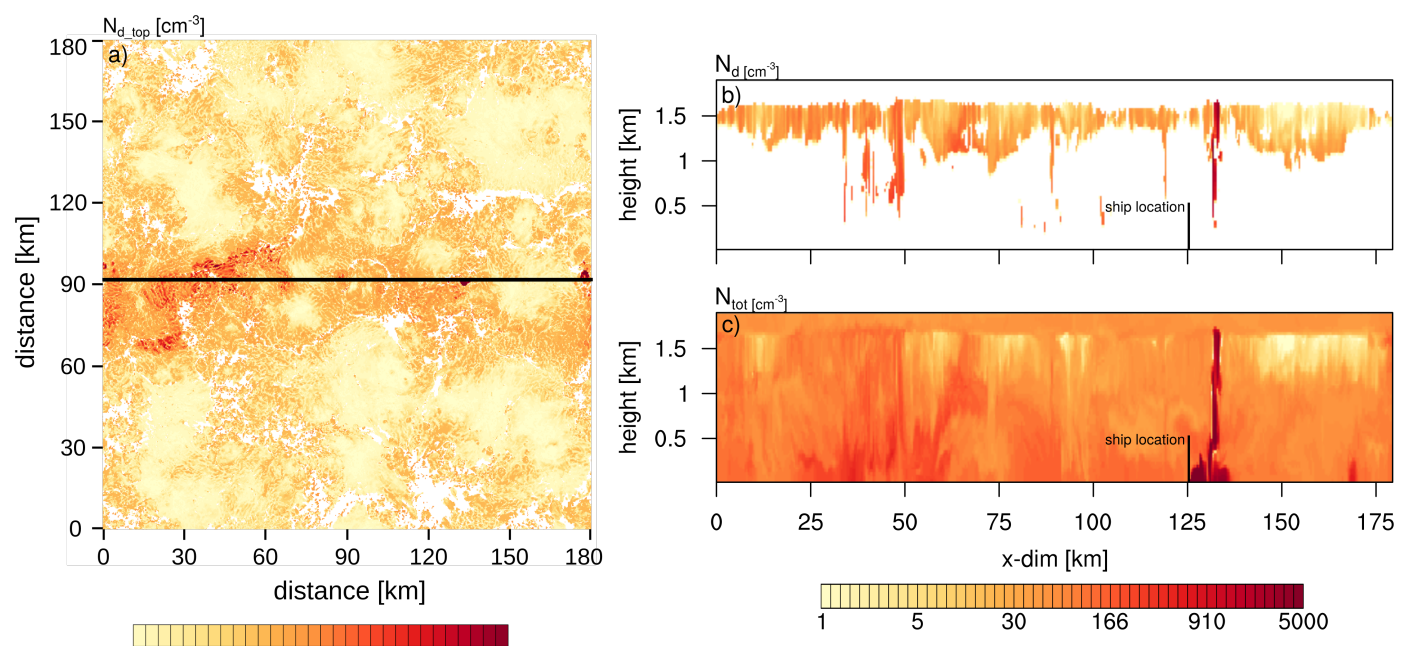

Figure S3. (a) instantaneous vertically integrated cloud droplet number concentration $\left(N_{d}\right)$ for the ship simulation. Black line denotes location of cross-sections shown in b-c). (b) $N_{d}$ and (c) total number concentration $\left(N_{\text {tot }}=N_{a}+N_{d}\right.$, where $N_{a}$ denotes the aerosol number concentration). Instantaneous location of ship is marked. 

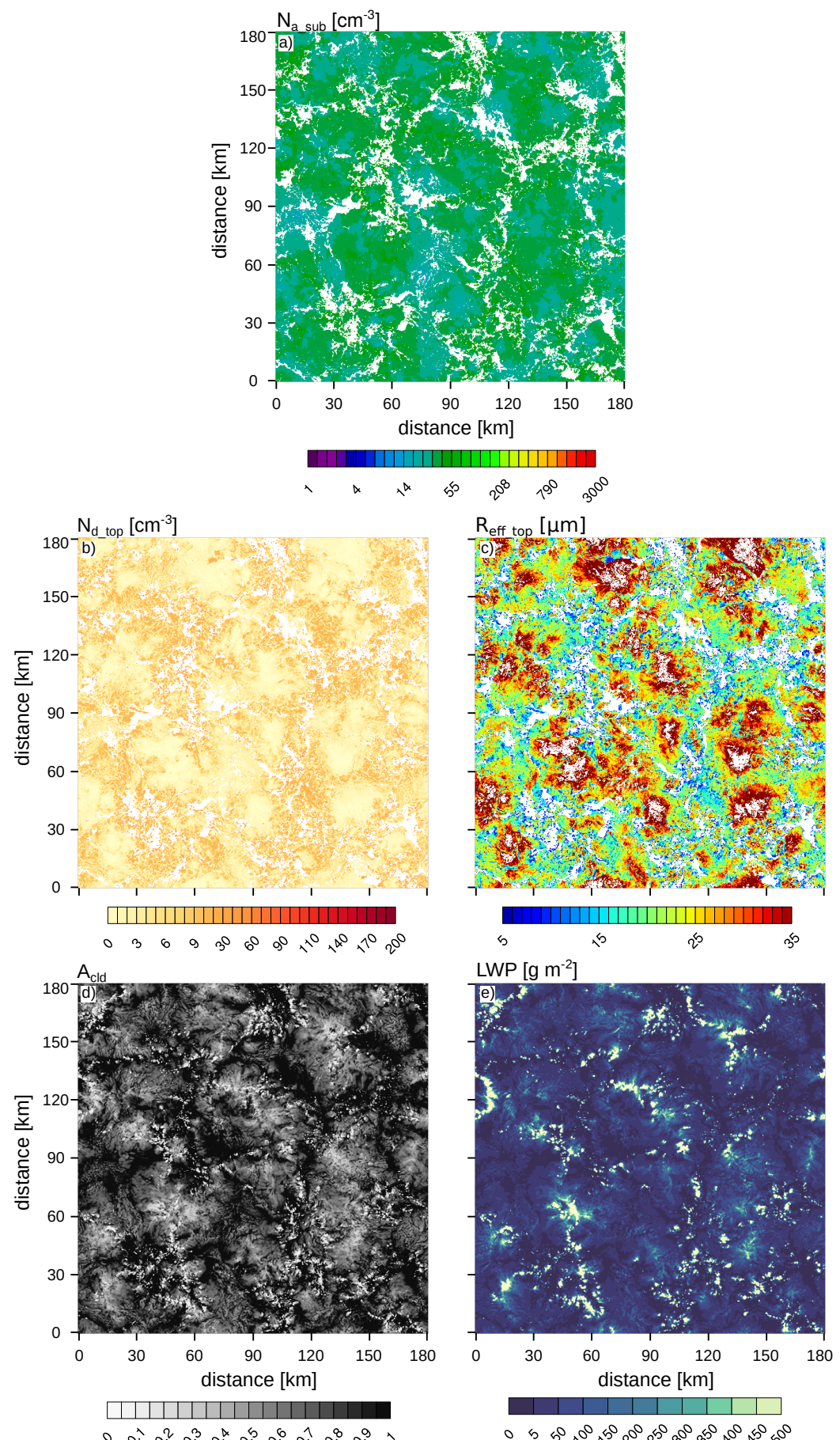

Figure S4. Same as Fig. 4 in manuscript, but for $c t r l$ simulation. 


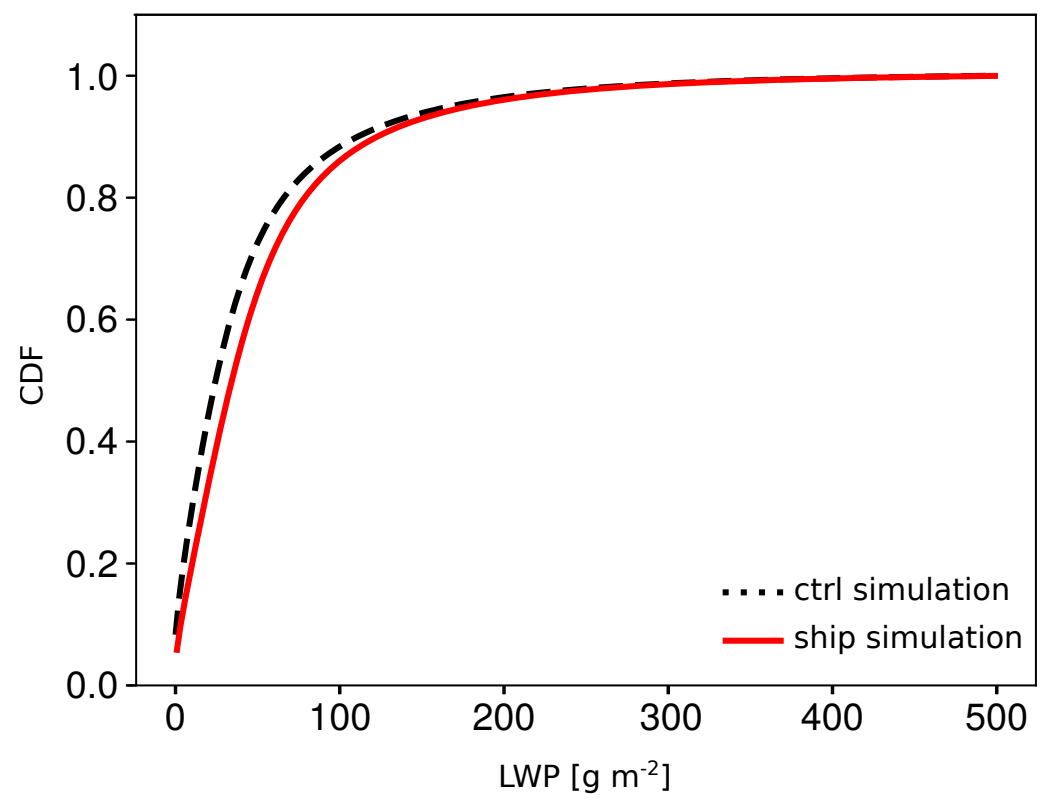

Figure S5. Cumulative distribution function $(\mathrm{CDF})$ of liquid water path $(L W P)$ for the $c t r l$ and the ship simulation. $\mathrm{CDF}$ is computed over detrained cloud regions only over the last $24 \mathrm{~h}$ of both simulations.

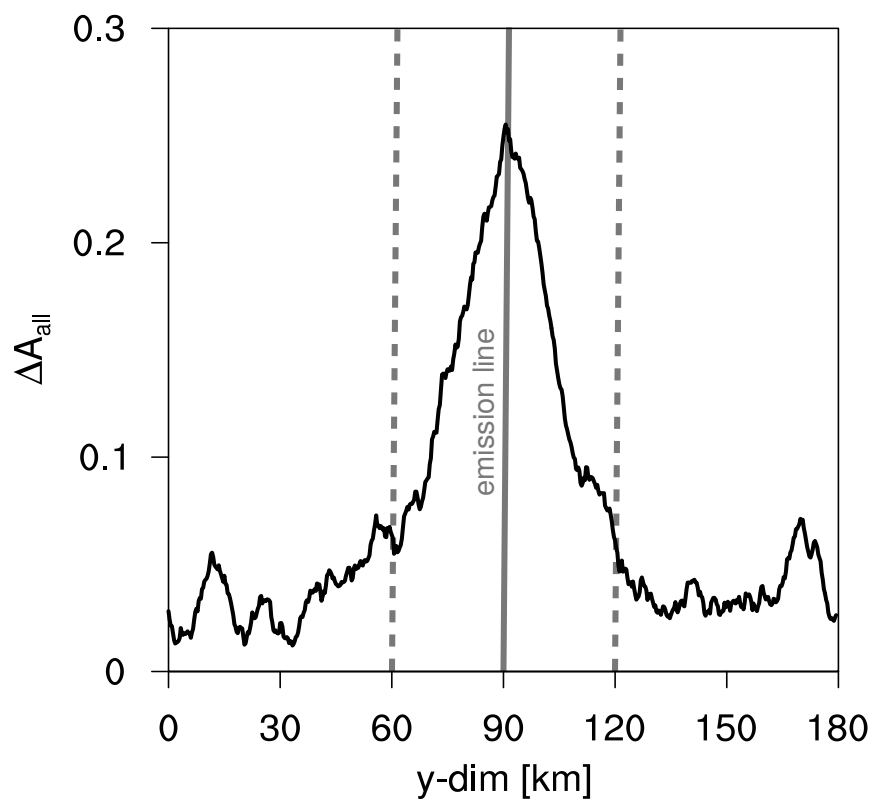

Figure S6. Across-track difference in all-sky albedo $\left(A_{\text {all }}\right)$ between the ship and $c t r l$ simulation averaged over the last $24 \mathrm{~h}$ of both simulations. Solid grey line denotes the location of the emission line of the ship, while grey dashed lines mark the seeded domain $( \pm 30 \mathrm{~km}$ from emission line). 

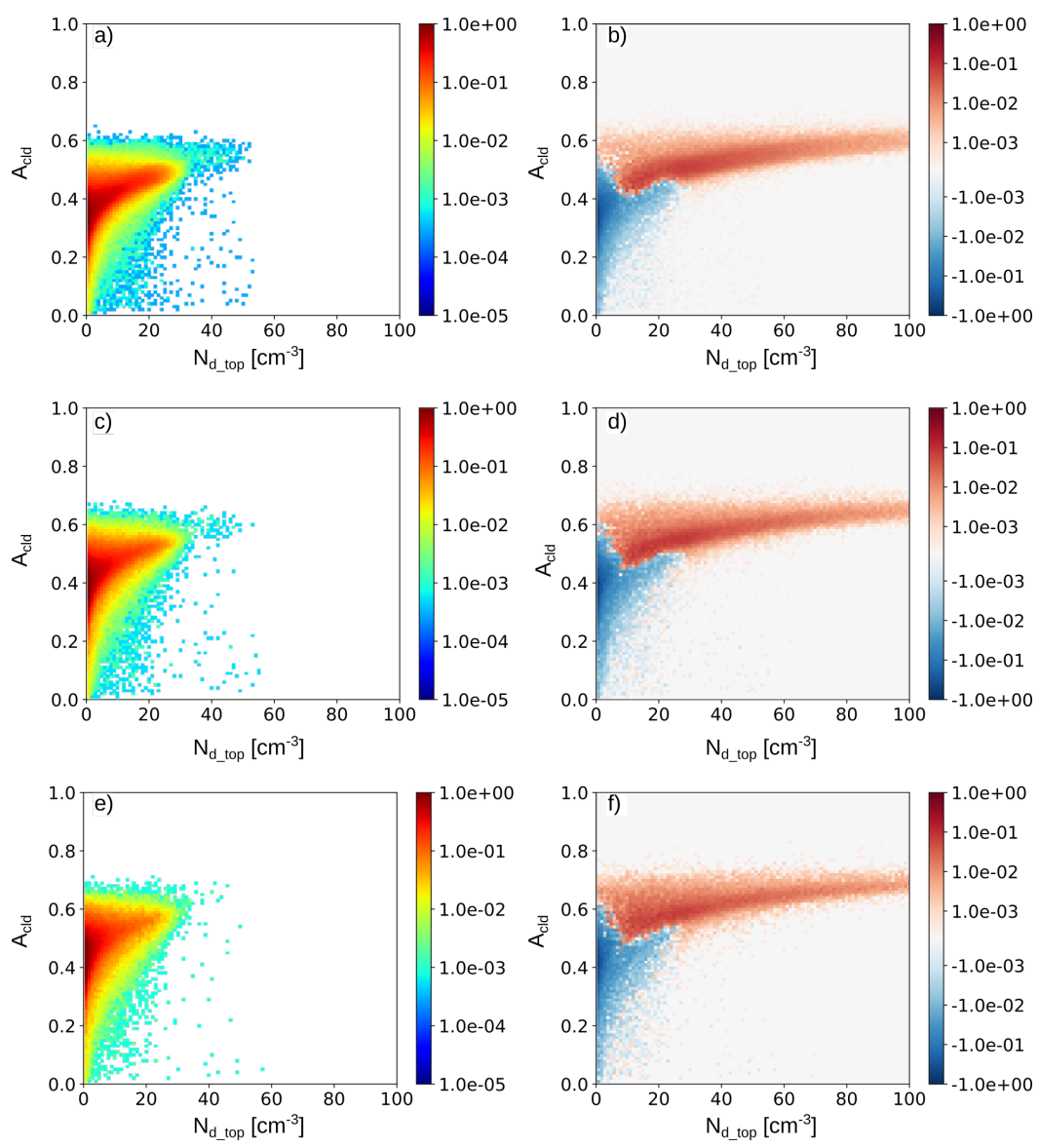

Figure S7. Occurrence rate F [\%] for the cloud-top droplet number concentration $\left(N_{d_{-} t o p}\right)$ versus cloud albedo ( $\left.A_{c l d}\right)$ phase space. The $N_{d \_t o p}-A_{c l d}$ space was sub-filtered for $L W P$ within the ranges of $60-80 \mathrm{~g} \mathrm{~m}^{-2}$ (top row), $80-100 \mathrm{~g} \mathrm{~m}^{-2}$ (middle row), and $100-$ $120 \mathrm{~g} \mathrm{~m}^{-2}$ (bottom row). Results are shown in a,c,e) for the last $24 \mathrm{~h}$ of the $\mathrm{ctrl}$ simulation and and absolute changes in $\mathrm{F}$ for the ship simulation with respect to the $c t r l$ simulation are shown in b,d,f). The bin widths for each of which $\mathrm{F}$ is defined are $\Delta N_{d \_t o p}: 1 \mathrm{~cm}^{-3}$, and $\Delta A_{\text {cld }}: 0.01$. 

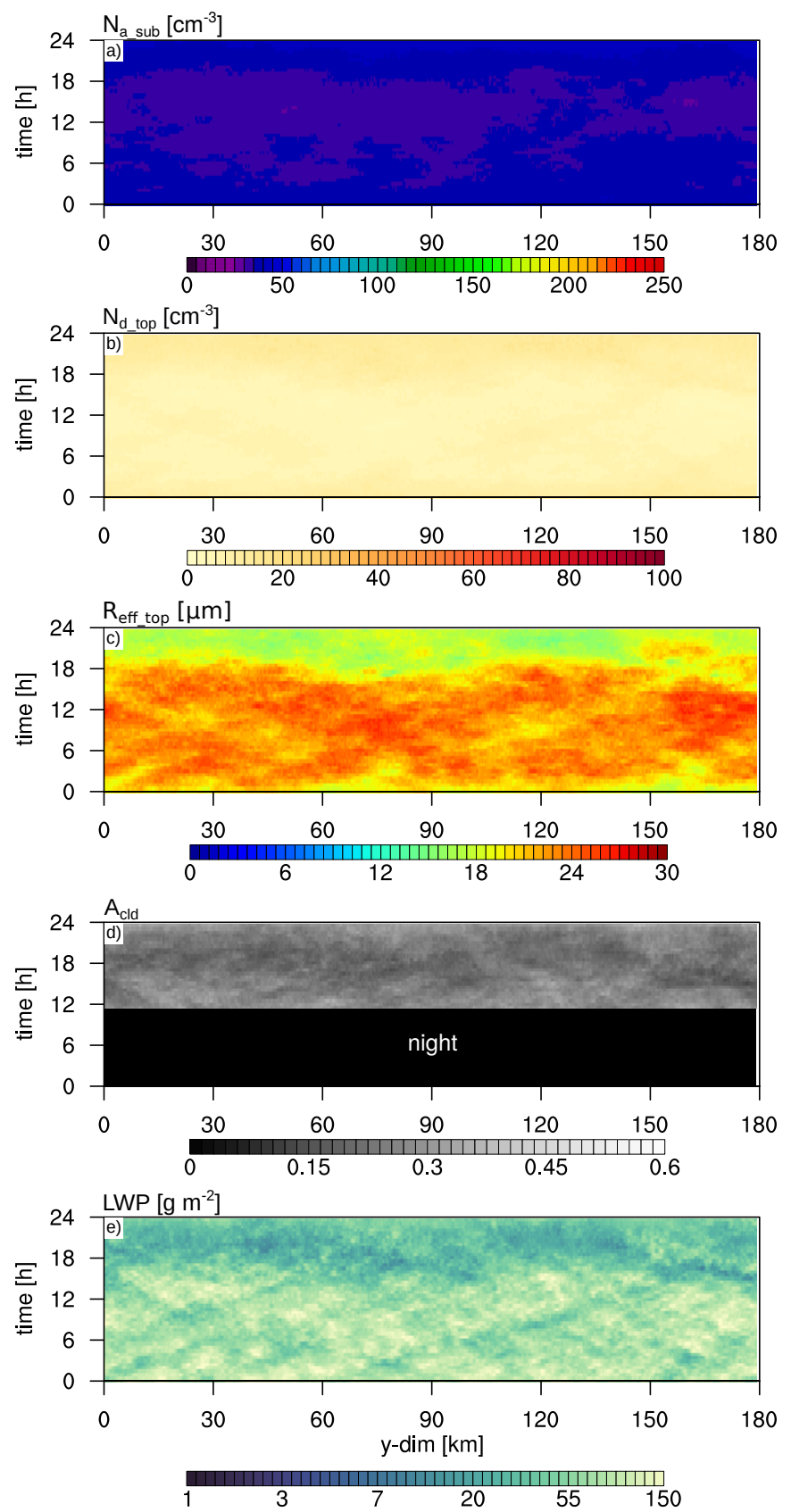

Figure S8. Same fields are shown as in Fig. 6 of manuscript, but for the clean simulation. 